\title{
Computational modelling of an Organic Rankine Cycle (ORC) waste heat recovery system for an aircraft engine
}

\author{
S. Saadon ${ }^{1}$ \\ ${ }^{I}$ Department of Aerospace Engineering, Faculty of Engineering, University Putra Malaysia, Malaysia
}

\begin{abstract}
Escalating fuel prices and carbon dioxide emission are causing new interest in methods to increase the thrust force of an aircraft engine with limitation of fuel consumption. One viable means is the conversion of exhaust engine waste heat to a more useful form of energy or to be used in the aircraft environmental system. A onedimensional analysis method has been proposed for the organic Rankine cycle (ORC) waste heat recovery system for turbofan engine in this paper. The paper contains two main parts: validation of the numerical model and a performance prediction of turbofan engine integrated to an ORC system. The cycle is compared with industrial waste heat recovery system from Hangzhou Chinen Steam Turbine Power CO., Ltd. The results show that thrust specific fuel consumption (TSFC) of the turbofan engine reach lowest value at $0.91 \mathrm{lbm} / \mathrm{lbf}$.h for $7000 \mathrm{lbf}$ of thrust force. When the system installation weight is applied, the system results in a $2.0 \%$ reduction in fuel burn. Hence implementation of ORC system for waste heat recovery to an aircraft engine can bring a great potential to the aviation industry.
\end{abstract}

\section{Introduction}

Growing consumption of primary fossil fuels and massive discharge of pollutants are some of the results caused by the world's growing population, and eventually the enlarging energy demand. It is therefore the main concerns that the developing world must face nowadays are the energy shortfall and the environmental destruction. Since 1973, the world energy consumption has been crucially increased and the world energy demands are growing up to $89 \%$ starting from 2006 till this year [1]. This affects significantly those industries which waste a huge amount of energy. And for these valid reasons the awareness of the use of the low-grade heat sources has captivated researchers around the world in recent years. To manage this matter, appropriate regulations should be established to further utilize the fossil energy and minimize the misuse energy in a more effective way. Particularly, there is extra effort in the aviation field to reach a higher quality of propulsion system, as the fuel cost is increasing and the future law is becoming more severe. It was recorded that the waste fuel energy from exhaust engine is over $30-40 \%$ and only a small fraction of this fuel energy which is roughly $12-25 \%$ were converted to useful work [2]. Apart from creating a downturn in fossil fuels market, waste heat recovery will also lead to reduction in greenhouse gases and hence making it the idea of a better future environment more promising.

There are a lot of discussions and researches emerge trying to prove that this waste heat recovery is a practical resource of energy due to its large quantity [3]. An example of steam-based waste heat recovery system applied to several industries is Heat Recovery Steam Generators (HRSGs). However, it is not recommended for a smaller gas turbine engine due to problems of weight as well as supply of water [4]. Hence an Organic Rankine Cycle (ORC) system has been proven to be one of the beneficial exhaust heat recovery technologies due to its small-scale and its undoubtedly potential integration in the next few years' power supply systems. A Rankine cycle is a heat engine thermodynamic cycle which converts the heat from a device for example turbine into mechanical work. In a Rankine cycle, the system applies the heat to rise up the temperature and pressure of an organic fluid. Thus, the name organic Rankine cycle comes from its use of an organic fluid which has a characteristic of a liquid-vapor phase change at a lower temperature than the phase change in water-steam. This allows heat recuperation of Rankine cycle from a lower temperature. Then this heat recovery can be converted into useful work which can be subsequently transforms into electricity.

Concerning the implementation of the ORC technology, various low-grade waste thermal energy industries such as solar energy, biomass energy, waste heat energy and geothermal energy have considered this system [5]. In power plant applications and marine diesel engine, there have been several researches concerning the thermal analysis and design optimization of an ORC using waste heat source [6-8] and recently a study had also been demonstrated experimentally [9]. Even so, to 
integrate the system to an aircraft engine, few factors must be taken into consideration. Principally, the aim of the system for a power plant is to recuperate a great amount of energy from the exhaust engine to supply electricity. However, in an aircraft engine the fundamental point is not to produce power, but to produce thrust and to reduce a considerable amount of fuel consumption. Bronicki et al., [4] also come up with the basis reasons for an ORC to be integrated to an aircraft gas turbine engine sized which marks about $16 \%$ of the gas turbine performance's improvement.

Conventionally, a small amount of air at a very high pressure is bled off from an aircraft engine and used to pressurize the cabin by providing air to the environmental control system. Bleed air is fundamentally loss of engine thrust as some air cannot be employed to produce thrust. Therefore, development of bleed less aircraft such as an engine driven electric compressor has started to influence the current technologies. However, this is quite misleading as electric devices need higher electricity power from engine. This is where the ORC system comes as solution. The system draws out waste heat from the turbofan's engine exhaust system and use it to supply electricity to operate the external air compressors to supply flow to the aircraft environmental control system or other aircraft systems. It is a recovery system that intends to increase the overall performance of the engine. As a result, a smaller amount of electricity power is needed from the aircraft engine, hence less fuel consumption, and this lower the engine bleed air and therefore a higher thrust could be achieved.

However, researches on design and performance analysis of an ORC waste heat recovery system integrated to aircraft engine and their possible advantages are still very few. Only one assessment study so far done by $\mathrm{C}$ A Perullo et al. [10]. They examined the feasibility and the benefits of an ORC heat recovery system to be used for inflight aircraft power generation. In this study, they utilize the Environmental Design Space (EDS) as the simulation tool $[11,12]$. The method applies a refine boiler situated inside the nozzle walls of an aircraft engine to extract heat from the engine exhaust. The organic fluid chosen to evaluate the system was R245fa because of its highest cycle energy performance across multiple operating pressure compare to other three possible fluids.

Nevertheless, because of limited time and resources, they decided to make several modeling assumptions. The researchers decided to use a fixed heat transfer coefficient to search for the off-design conditions and they estimated a pressure loss only in the turbine and although the engine fluid flow progress during the engine running, they assumed a fixed core exhaust flow of 30\% that links to the evaporator. Consequently, about $0.9 \%$ fuel burn savings is possible but it depends on the whole engine system weight. However, their aim is not to analyze the thermal performance, in terms of how the heat transfer being produced, and the overall performance of the system; hence, a very brief presentation of the model was provided. A more recent study done by Saadon et al., [13] tried to understand clearly the thermodynamic behavior of the ORC system when connected to exhaust turbofan engine. However, their analysis is still very loose in the aim to understand clearly the main cause of such behavior and the impact of the ORC system to the aircraft was not done. Therefore, this study differs from the previous in the following: (i) the detailed study on the heat transfer process of the ORC system conducted and its algorithm; (ii) the analytical study of their thermal performance; (iii) the evaluation of the Thrust Specific Fuel Consumption (TSFC) of the aircraft engine and the fuel burn.

\section{Numerical model of ORC integrated to an aircraft exhaust engine}

An ORC system integrated with an aircraft exhaust engine is presented in a diagram in Fig. 1 which consists of an evaporator, a turbine, a condenser, a working fluid pump and a regenerator that is used to heat up the organic fluid before getting into the evaporator to achieve a better thermal efficiency of the system. Here, the working fluid is the organic fluid. The Rankine cycle is connected to the aircraft engine at the middle of the low-pressure turbine exit duct and the core nozzle. Fig. 1 below shows the link between the aircraft engine and the ORC system which is based at the evaporator. The system starts at the outlet of the liquid side of the regenerator (station 1). An inlet temperature of the working fluid to the evaporator $T_{E V, W F_{-} I n}(i)$ is assumed and the system is performed.

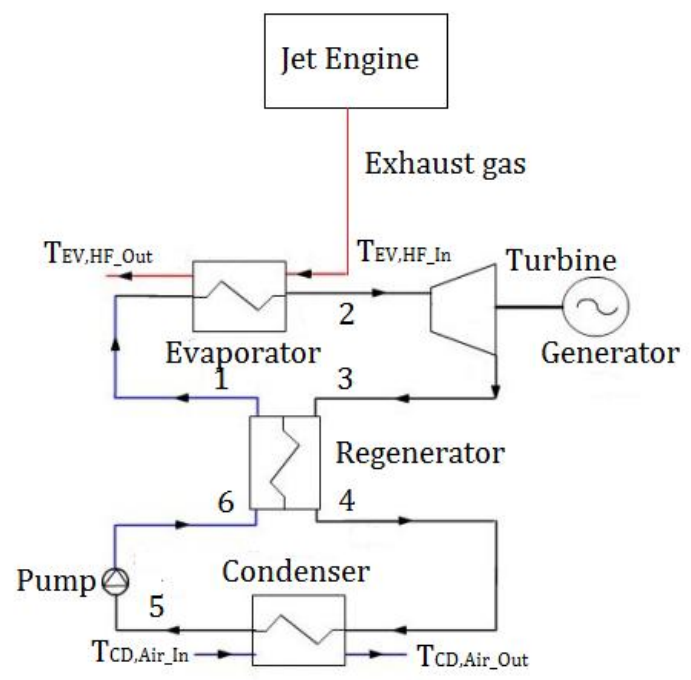

Figure 1. Schematic diagram of the ORC system with regenerator integrated to an aircraft engine. [13]

The ORC system is presented in a T-s (temperatureentropy) diagram as in Fig. 2 below. A shell-tube heat exchanger is chosen as the evaporator as it is the most demanded in many industries and is convenient for higher-pressure applications. It consists of a shell with several tubes inside. The heat is transferred between the two fluids through the tube wall within the shell by entering one fluid inside the tubes, while the other fluid flows outside the tubes. 
To model the evaporator, there are three methods of modelling that can be applied to evaluate the heat transfer of the evaporator. They are distributed modelling, zone modelling and single node lump modelling methods $\mathrm{J}$ Sun and $\mathrm{W}$ Li [8]. The single node lump modelling approach assumes that the temperature difference inside each node is negligible and this implies that the constant specific heat inside is unchanged too. Hence it is normally not possible for this ORC application where liquid-vapor phase change occurs. Meanwhile, with zone modelling, the evaporator is separated into three different zones which are super-heat, two-phase and sub-cool zones. Consequently, the single node lump method can be applied to each zone. However, a vigorous iterative algorithm is required to attain the heat transfer surface area of each zone. Otherwise, a distributed modelling method treats the evaporator as small divisions starting from where the flow enters until towards the outlet. Then eventually, the single node lump method, here it is NTU (Number of Transfer Units) method, can be applied in each division for evaluation of heat and mass transfers. This distributed modelling method is more accurate compared to the first two methods. In this paper, the distributed method is applied to model the evaporator.

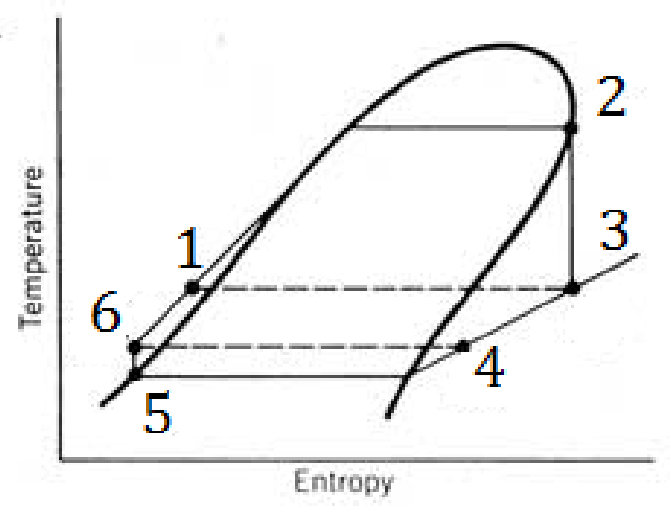

Figure 2. T-s diagram of the ORC system with regenerator.

Fig. 3 below shows the three consecutive parts, noted $i-1, i$ and $i+1$. By using the distributed modelling method, it is adequate to assume that the heat capacity of the waste heat engine and organic fluid are roughly invariable in each discrete division. Therefore, to construct a numerical model for each single segment, the NTU method is applied. For each segment $i$, the enthalpy of the organic fluid is supposed to be increased because the heat is absorbed from the exhaust engine. Consequently, the heat transfer rate of each segment is sum up to get the total heat transfer of the evaporator.

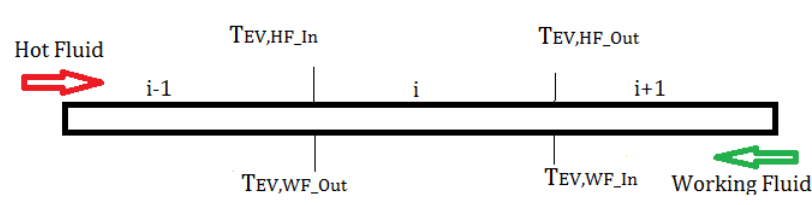

Figure 3. Discrete segments of evaporator. [13]

$$
q_{E V, W F}(i)=\dot{m}_{E V, W F}\left[h_{E V, W F \_O u t}(i)-h_{E V, W F_{-} I n}(i)\right]
$$

According to the Eq. 1, $q_{E V, W F}(i), \dot{m}_{E V, W F}$, $h_{E V, W F \_ \text {out }}(i)$ and $h_{E V, W F_{\text {In }}}(i)$ are heat transfer rate, mass flow rate and inlet and outlet enthalpies respectively of the organic fluid for the section $i$.

Similarly, the heat transfer rate for the exhaust gas, $q_{E V, H F}(i)$ is noted as,

$$
q_{E V, H F}(i)=\dot{m}_{E V, H F} C_{p, E V, H F}(i)\left[T_{E V, H F_{-} I n}(i)-T_{E V, H F_{-} O u t}(i)\right]
$$

Here, $C_{p, E V, H F}(i), m_{E V, H F}, T_{E V, H F_{-} I n}(i)$ and $T_{E V, H F}$ Out $(i)$ are specific heat, mass flow rate and entrance and exit temperatures respectively of the exhaust gas for the section $i$.

The maximum heat transfer rate $q_{E V, M A X}(i)$, throughout the evaporator can be written as,

$q_{E V, M A X}(i)=C_{E V, M I N}(i)\left[T_{E V, H F_{-} I n}(i)-T_{E V, W F_{-} I n}(i)\right]$ (3) with

$C_{E V, M I N}(i)=\operatorname{MIN}\left\{\dot{m}_{E V, W F} C_{p, E V, W F}(i), \dot{m}_{E V, H F} C_{p, E V, H F}(i)\right\}(4)$

Meanwhile, the effectiveness $\varepsilon_{E V}(i)$ can be defined as [14],

$\varepsilon_{E V}(i)=$

$\left.\left\{2 \times\left\{\left[1+C_{r}(i)+\left(1+C_{r}^{2}(i)\right)^{0.5}\right] \times \frac{1+\exp \left[-N T U(i) \times\left(1+C^{2}{ }_{V}(i)\right)^{0.5}\right.}{1-\exp \left[-N T U(i) \times\left(1+C_{r}^{2}(i)\right)^{0.5}\right]}\right]\right\}\right\}$

(5)

where $\quad C_{r, E V}(i)=\frac{C_{E V, M I N}(i)}{C_{E V, M A X}(i)}$

$C_{E V, M A X}(i)=\operatorname{MAX}\left\{\dot{m}_{E V, W F} C_{p, E V, W F}(i), \dot{m}_{E V, H F} C_{p, E V, H F}(i)\right\}$

$N T U(i)$ is computed as,

$$
N T U(i)=\frac{U(i) A_{E V}(i)}{C_{E V, M I N}(i)}
$$

The total heat transfer rate of the evaporator $Q_{E V}$,

$$
Q_{E V}=\sum_{i=1}^{N_{E V}} q_{E V}(i)
$$

where $N_{E V}$ is the total of evaporator segments.

The pump power comsumption in process 5 to 6 is defined by 


$$
W_{\text {pump }}=\frac{\dot{m_{W F} C p_{W F}\left(\Pi^{\frac{\gamma-1}{\gamma}}-1\right)}}{\eta_{\text {pump }}}
$$

where $\Pi=\frac{P_{2}}{P_{1}}, \eta_{\text {pump }}$ is the efficiency of the pump and $\gamma$ is the specific heat ratio of the organic fluid.

When the organic fluid exits the pump as a saturated or superheated fluid and flows through the turbine, the power is produced and exits from the turbine as low pressure superheat fluid. Then the turbine power output is obtained from,

$$
W_{\exp }=\dot{m_{W F}} C p_{W F} \eta_{\exp } T_{\exp \_i n}\left(1-\Pi^{\frac{1-\gamma}{\gamma}}\right)
$$

where is $T_{\text {exp_in }}$ the turbine inlet temperature and $\eta_{\exp }$ is the efficiency of the turbine.

The net power output is then

$$
W_{n e t}=W_{\exp }-W_{\text {pump }}
$$

And the thermal efficiency of the ORC system is

$$
\eta_{n e t}=\frac{W_{\exp }-W_{p u m p}}{Q_{E V}}
$$

The total of fuel (kerosene) that could be eventually saved is

$$
\dot{m}_{\text {fuel }}=\frac{Q_{E V}}{H V_{\text {fuel }}}
$$

where HVfuel is the heating value of kerosene, HVfuel = $43,000 \mathrm{~kJ} / \mathrm{kg}$.

As the thermal model of the evaporator depends on the effectiveness of the heat exchanger, and this effectiveness itself depends on the $N T U_{E V}$, the total heat transfer rate of the evaporator is found numerically by iteration. The procedure is illustrated by the flow chart in Fig. 4. The calculation commences with an initial estimation of $N T U_{E V}$. The corresponding organic fluid mass flow rate and heat capacity of both fluids are then calculated, which allows determine the new value of $N T U_{E V}$ and $C_{r, E V}$ for each zone. The evaporator effectiveness is then evaluated for each zone. For the first zone, the initial organic fluid mass flow rate is taken as the inlet value. For subsequent zones, the inlet mass flow rate is given by the outlet mass flow rate of the upstream zone. These steps are repeated until the difference between the effectiveness calculated for two consecutive iterations is less than $0.1 \%$. Finally, the heat transfer rate for each zone is calculated and the total heat transfer of the evaporator is attained.

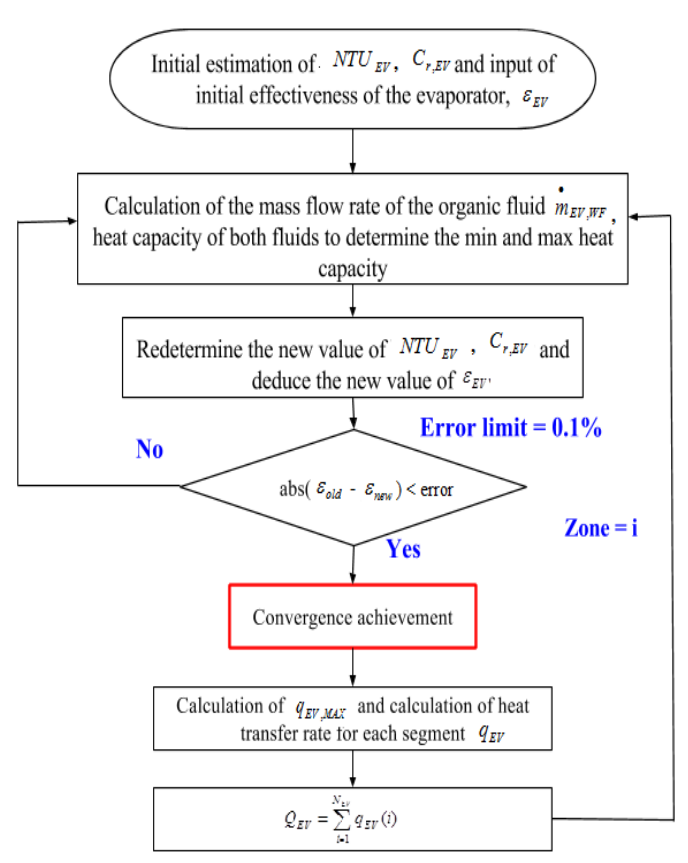

Figure 4. Algorithm of calculation of the total heat transfer rate.

\section{Validation of a thermal model}

With the intention to validate the numerical model constructed, the ORC model was first compared to the one for industrial waste heat recovery [15] with R123 at cooling water temperature, Tc,in of $293 \mathrm{~K}$ and $303 \mathrm{~K}$. The selected waste heat source is the low temperature steam from Hangzhou Chinen Steam Turbine Power CO., Ltd and is depicted in Table 1 below. The specific heat of R123 in the range of the design temperature value is $0.9744 \mathrm{~kJ} / \mathrm{kg} . \mathrm{K}$, while for kerosene, it is said to be 2.01 $\mathrm{kJ} / \mathrm{kg} . \mathrm{K}$. The simulation software is independently developed by the researchers through MATLAB. A simulation is then performed by using the mathematical equations defined above, with inlet temperature of R123 at $100 \mathrm{~K}$.

The model was validated by comparing the results of net power output and system thermal efficiency with the previously published results and these results are presented in Fig. 5 and Fig. 6. It is noted that the net power output and thermal efficiency vary with the inlet temperature heat source. It can be observed that there is a slight deviation compared to the results achieved by Jian Song et al. [15], occurred at higher temperature level of the heat source. These may be resulted from the constant inlet organic fluid assumed in the simulation. Basically, the inlet temperature of R123 will vary with the environmental and factory conditions. The relative error of the results obtained compared to works done by Jian et al. [15] for Tc,in $=293 \mathrm{~K}$ is $0.43 \%$, while for $\mathrm{Tc}, \mathrm{in}=303$ $\mathrm{K}$, the discrepancies is a bit higher at $10.15 \%$. However, for the aircraft engine which the ORC is going to be applied to in the following section, the inlet temperature of the organic fluid used will be given by the engine data and the value is fixed for the design point. As a whole, the numerical solutions obtained in this study are consistent with those reported in Jian Song et al. [15]. 
Table 1. Design parameters of ORC system with R123 as the working fluid.

\begin{tabular}{|l|c|r|}
\hline Description & Unit & Value \\
\hline $\begin{array}{l}\text { Mass flow } \\
\text { rate of R123 }\end{array}$ & $\mathrm{kg} / \mathrm{s}$ & 453 \\
\hline $\begin{array}{l}\text { Heat source } \\
\text { inlet } \\
\text { temperature }\end{array}$ & $\mathrm{K}$ & 350 \\
\hline $\begin{array}{l}\text { Evaporation } \\
\text { temperature }\end{array}$ & $\mathrm{K}$ & 1.21 \\
\hline $\begin{array}{l}\text { Turbine } \\
\text { inlet } \\
\text { pressure }\end{array}$ & $\mathrm{MPa}$ & 0.55 \\
\hline $\begin{array}{l}\text { Turbine } \\
\text { outlet } \\
\text { pressure }\end{array}$ & $\mathrm{MPa}$ & 0.6 \\
\hline $\begin{array}{l}\text { Turbine } \\
\text { efficiency }\end{array}$ & - & 12.7 \\
\hline $\begin{array}{l}\text { Pump } \\
\text { efficiency }\end{array}$ & $\mathrm{kW}$ & 0.8 \\
\hline $\begin{array}{l}\text { Net power } \\
\text { output }\end{array}$ & - & 529 \\
\hline $\begin{array}{l}\text { System } \\
\text { thermal } \\
\text { efficiency }\end{array}$ & & \\
\hline
\end{tabular}

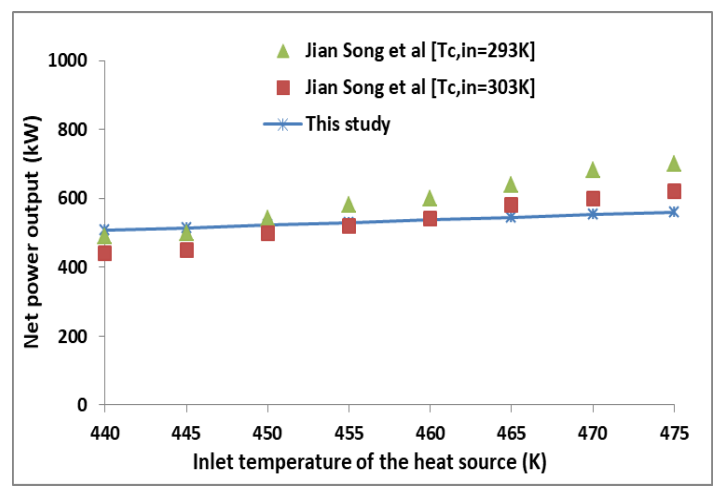

Figure 5. Variations of the net power output of the ORC system with heat source inlet temperature.

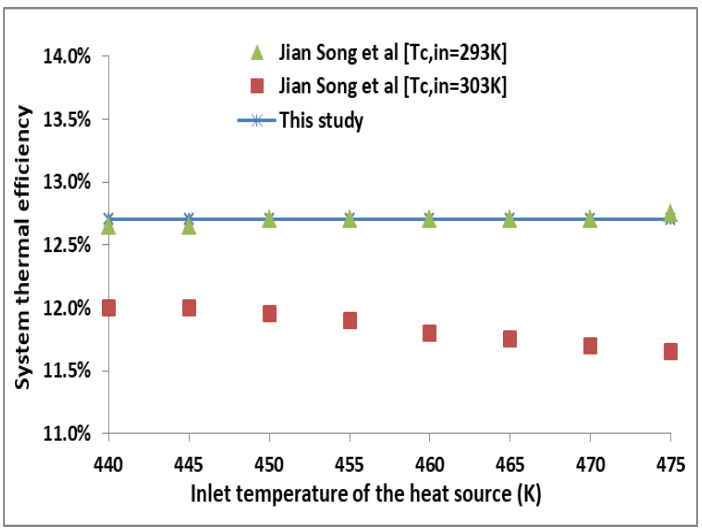

Figure 6. Variations of the system thermal efficiencies of the ORC system with heat source inlet temperature.

\section{ORC integrated to an aircraft exhaust engine}

This part presents the advantages of ORC system integrated to a CFM56-7B27 turbofan engine on an aircraft size of 737-800. The working fluid chosen is the $\mathrm{R} 245 \mathrm{fa}$. The specific heat of R245fa in the range of the design temperature value is $1.36 \mathrm{~kJ} / \mathrm{kg} . \mathrm{K}$. Design parameters are listed in Table 2 below [10]. In order to solve this system, the heat transfer flowing out from the exhaust engine is varied until it matches the heat transfer calculated using the heat transfer coefficient and evaporator area from the detailed design. By doing this, it ensures that the evaporator exit temperature set by the thermodynamic limits of $\mathrm{R} 245 \mathrm{fa}$ is maintained. The simulation is then executed as before and the results attained are presented in figure below.

Table 2. Main parameter of the ORC system for the turbofan engine

\begin{tabular}{|l|c|c|}
\hline Description & Unit & Value \\
\hline $\begin{array}{l}\text { Mass flow } \\
\text { rate of } \\
\text { R245fa }\end{array}$ & $\mathrm{kg} / \mathrm{s}$ & 3.84 \\
\hline $\begin{array}{l}\text { Estimated } \\
\text { required } \\
\text { surface area } \\
\text { of } \\
\text { evaporator }\end{array}$ & $\mathrm{m}^{2}$ & 23.72 \\
\hline $\begin{array}{l}\text { Required } \\
\text { heat transfer } \\
\text { of } \\
\text { evaporator }\end{array}$ & $\mathrm{kW}$ & 1105 \\
\hline $\begin{array}{l}\text { Exhaust } \\
\text { heat } \\
\text { temperature }\end{array}$ & $\mathrm{K}$ & 843 \\
\hline $\begin{array}{l}\text { Inlet } \\
\text { temperature } \\
\text { of R245fa }\end{array}$ & $\mathrm{K}$ & 392 \\
\hline $\begin{array}{l}\text { Outlet } \\
\text { temperature } \\
\text { of R245fa }\end{array}$ & $\mathrm{K}$ & 0.70 \\
\hline $\begin{array}{l}\text { Turbine } \\
\text { inlet } \\
\text { temperature }\end{array}$ & & 393 \\
\hline $\begin{array}{l}\text { Turbine } \\
\text { inlet } \\
\text { pressure }\end{array}$ & $\mathrm{MPa}$ & \\
\hline $\begin{array}{l}\text { Turbine } \\
\text { outlet } \\
\text { pressure }\end{array}$ & & \\
\hline $\begin{array}{l}\text { Turbine } \\
\text { efficiency }\end{array}$ & & \\
\hline $\begin{array}{l}\text { Pump } \\
\text { efficiency }\end{array}$ & & \\
\hline
\end{tabular}

The turbine within the ORC was connected to a simulation of an external compressor in order to evaluate 
the impact on the engine when engine bleed air was reduced. The result shown below in Fig. 7 is detail common cruise conditions with Mach 0.785 at altitude of 35,000 feet. Even with the small loss in core thrust this reduces the TSFC below the base cycle by an average of $3.1 \%$, defined in Fig. 7 by "Regen + Bleed Savings".

Once the feasibility of the idea of implementing the ORC on an engine basis was confirmed, it was required to estimate the advantages on the combined engine and aircraft system. Fig. 8 described the fuel burn relative to the base cycle and takes into account the vehicle weight throughout the flight. The "Regen + Bleed Savings" scenario show the fuel burn effect only from the TSFC change whereas the "Add $950 \mathrm{lbm}$ per engine" scenario assumes a nominal weight impact of $950 \mathrm{lbm}$ on the detailed ORC system. When the system installation weight is applied, the system results in a $2.0 \%$ reduction in fuel burn.

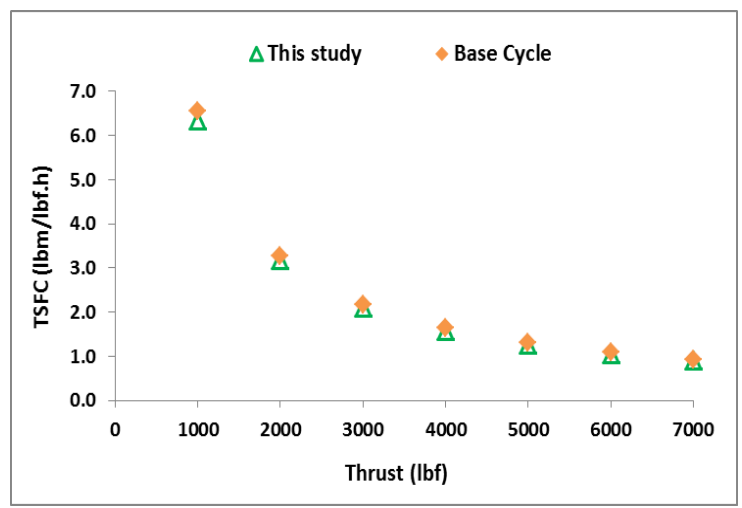

Figure 7. ORC engine with TSFC effects and ORC impact on mission fuel burn

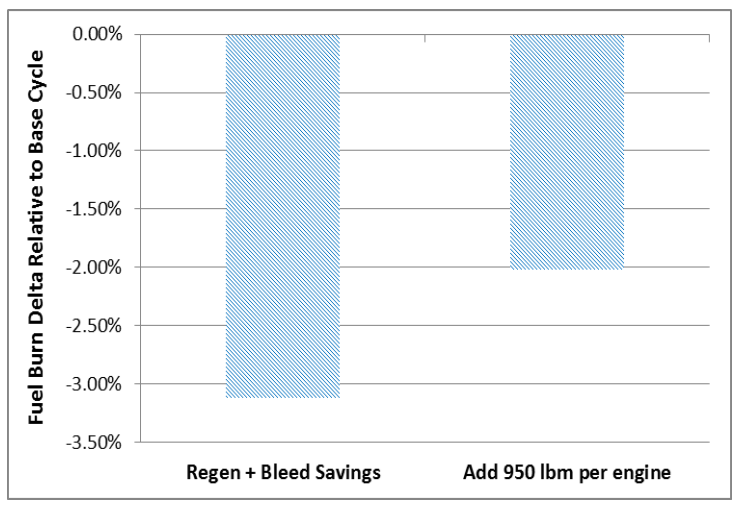

Figure 8. ORC engine with TSFC effects and ORC impact on mission fuel burn

\section{Conclusions}

This paper presents a detailed study of a one-dimensional analysis method of ORC system implemented in an aircraft engine. A numerical model for the system has been modified from previous authors' work. The model features include an algorithm of calculation of the total heat transfer rate driven by the NTU method. Validation with other researchers' work for an industrial waste heat recovery shows a reasonable agreement with net output power and thermal efficiency although some discrepancies could be found at higher inlet heat source temperature of the evaporator. These discrepancies can partly be attributed to the assumption of lower organic fluid inlet temperature of the evaporator which results in lower mass flow rate of the fluid. At the same time the simulation model needs more parameters to be defined which increases the variabilities in the simulation estimations.

The initial results for the ORC system integrated to a turbofan's exhaust engine provide an idea of the impact of this system on the engine's thrust and its fuel consumption. Parametric optimization shall be conducted in future in order to maximize the total heat transfer rate through the evaporator. Such results will be very useful in future to determine the irreversibility losses through calculation of exergy of each ORC component in order to achieve an optimize system performance and eventually higher thrust power. The presented research proved that an ORC cycle with regenerator gives potential advantages when integrated to an aircraft engine and used to provide electrical power to the aircraft.

\section{References}

1. M. Abdolzadeh, M. Sadeqkhani, A. Ahmadi, Energy, 133, 998-1012, (2017)

2. M. Hasanuzzaman, N.A. Rahim, R. Saidur and S.N Kazi, , 36, 233-240, (2011)

3. D. Ziviani, A. Beyene, and M. Venturini, Applied Energy, 121, 79-95, (2014)

4. L.Y. Bronicki and D.N. Schochet, Proceedings ASME Turbo Expo, 5, 79-86 (GT2005-68121)

5. B.F. Tchanche, G. Lambrino, A. Frangoudakis and G. Papadakis, Renewable \& Sustainable Energy Reviews, 15, 79-95 (2011)

6. J. Song, Y. Song and C.W. Gu, Energy, 82, 976-98, (2015)

7. M.H. Yang and R.H. Yeh, Applied Energy, 149, 112, (2015)

8. J. Sun and W. Li, Applied Thermal Energy, 31, 2032-2041, (2011)

9. W. Pu, C. Yue, D. Han, W. He, X. Liu, Q. Zhang and Y. Chen, Applied Thermal Engineering, 94, 221-227, (2016)

10. C.A. Perullo, D.N. Mavris and E. Fonseca, Proceedings of ASME Turbo Expo. Turbine Technical Conference and Exposition, (2013)

11. M. Kirby and D. Mavris, $26^{\text {th }}$ International Congress of the Aeronautical Sciences, (2008)

12. J. Schutte, J. Tai and D. Mavris, $48^{\text {th }}$ AIAA/ASME/SAE/ASEE Joint Propulsion Conference \& Exhibitition, (2012)

13. S. Saadon and A.R. Abu Talib, IOP Conference Series: Materials Science and Engineering, 152, Number 1, (2016)

14. J.P. Holman, Heat Transfer, sixth ed. McGraw-Hill Book Company, New York, (1986)

15. J. Song, C. Gu and X. Ren, Energy Conversion and Management, 112, 157-165, (2016) 